\title{
Experimental Study on Electrochemical Softening for Cooling Circulating Water in Converter Station
}

\author{
Xia Zhu ${ }^{1,2^{*}}$, Xiaoyu Liu ${ }^{1,2}$, Ying Tian ${ }^{1,2}$, Zhengkun Li $^{1,2}$, Zhenhua Ren ${ }^{1,2}$, Juan Wang ${ }^{1,2}$, Sufei Liu ${ }^{1,2}$, Can Wang ${ }^{1,2}$, and Shuai \\ $\mathrm{Du}^{1,2}$ \\ ${ }^{1}$ Nari Group Corporation/State Grid Electric Power Research Institute, Nanjing 210000, Jiangsu Province, China \\ ${ }^{2}$ Beijing Guodian Futong Science and Technology Development Co., Ltd., Beijing 100070, China
}

\begin{abstract}
In this study, the electrochemical softening method was used to treat the simulated drainage of the converter station, and the treatment effect under different water inlet conditions was investigated. The results show that the hardness removal rate is from $10 \%$ to $80 \%$ when the residence time is from $0.5 \mathrm{~h}$ to $4 \mathrm{~h}$, and the longer the residence time is, the higher the removal rate is. The maximum scale removal capacity reached $2.67 \mathrm{~g} / \mathrm{h} / \mathrm{m}^{2}$ when residence time was $1 \mathrm{~h}$. Through the formula fitting of several groups of tests, it is concluded that the removal effect can be expressed by the formula $\mathrm{C} 0 / \mathrm{C}=0.9627 \mathrm{e}^{(17.73 \mathrm{at} / \mathrm{V})}$ under different water intake (residence time).
\end{abstract}

\section{Preface}

Most converter stations are located in remote areas, with no drainage networks nearby or far from these networks, and no suitable receiving water body. Moreover, the natural environment in which they are located is very fragile, so they are extremely sensitive to the discharge of pollutants around them. Therefore, it is an effective solution to dispose the drainage outside the converter station and recycle it.

The chlorine ion and hardness of the drainage of the converter station are high, so the water needs to be softened first and then reduced in the back section. However, due to its complex process and high annual cost, the use of chemical agent method, which is widely used at present, has been greatly restricted in recent years[1,2].

Electrochemical descaling technology is a kind of active descaling processing technology, The technology is to generate a large number of carbonic acid near the cathode plate through electrolysis. When calcium and magnesium ions migrate to the cathode, they combine with carbonic acid to form precipitation, so as to reduce the hardness of water and avoid or reduce scaling on the equipment $[3,4]$.

In order to study the effect of electrochemical scale removal technology on the drainage treatment of converter station, a small experimental device was set up in this study to investigate the effect of post-treatment under different feeding conditions in the device, so as to accumulate experience for the practical engineering of the drainage treatment of converter station in the future.

\section{The experiment part}

\subsection{The experimental system}

The system flow chart is shown in Figure 1, including water inlet tank, electrolysis device and water inlet pump. The water sample is driven into the descaling equipment from the water inlet pump. There is an overflow port at the top of the descaling equipment. The water in the equipment is full and directly overflows out of the equipment.

The internal size of descaling equipment is $400 * 430 *$ $370 \mathrm{~mm}$, and the water volume is $60 \mathrm{~L}$; The anode plate is made of ruthenium-iridium coated titanium substrate plate with a network structure and a surface area of $0.95 \mathrm{~m}^{2}$. The cathode plate is carbon steel, and the entire inner wall of the equipment is also used as the cathode. The total area of the cathode is $1.59 \mathrm{~m}^{2}$. The experiment uses DC power supply, the specification is $24 \mathrm{~V}, 40 \mathrm{~A}$.

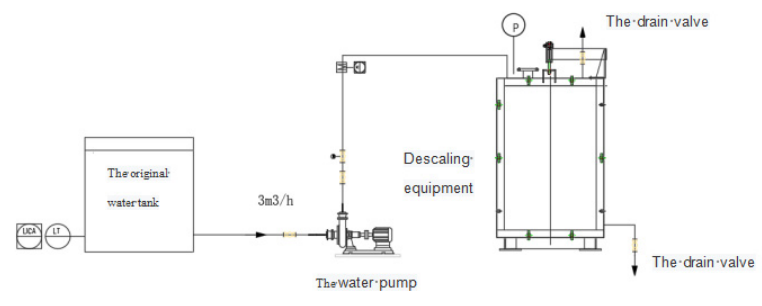

Figure 1. Flow chart of experiment

$\overline{{ }^{*} \text { Corresponding author: 592232002@qq.com }}$ 


\subsection{The experimental method}

\subsubsection{Preparation of water samples}

The experimental water was configured with tap water and analytical pure drugs from Sinopharm Group. Specifically, $\mathrm{NaHCO} 3$ was used to adjust the basicity, making the relationship between basicity and hardness $1: 1$, and $\mathrm{NaCl}$ was used to adjust the electrical conductivity to $1500 \mu \mathrm{s} / \mathrm{cm}$. Actual water quality indexes after water distribution are shown in the table 1 below.

Table 1. Water quality

\begin{tabular}{|l|l|}
\hline & Water quality \\
\hline $\mathrm{pH}$ & 8.55 \\
\hline Electrical conductivity $(\mu \mathrm{s} / \mathrm{cm})$ & 1497 \\
\hline Total hardness $(\mathrm{mg} / \mathrm{L})$ & 236 \\
\hline Calcium ions $(\mathrm{mg} / \mathrm{L})$ & 52.8 \\
\hline Magnesium ions $(\mathrm{mg} / \mathrm{L})$ & 25.8 \\
\hline The chloride ion $(\mathrm{mg} / \mathrm{L})$ & 308 \\
\hline Total alkalinity $(\mathrm{mg} / \mathrm{L})$ & 257 \\
\hline Carbonic acid root $(\mathrm{mg} / \mathrm{L})$ & 7.0 \\
\hline Bicarbonate root $(\mathrm{mg} / \mathrm{L})$ & 285 \\
\hline
\end{tabular}

\subsubsection{Power Settings}

Constant current operation, the current is $23.85 \mathrm{~A}$, the current density is about $15 \mathrm{~A} / \mathrm{m}^{2}[5,6]$.

\subsubsection{The water conditions}

Carry out the test according to the incoming water conditions in the table 2.

Table 2. Incoming water condition

\begin{tabular}{|c|c|c|}
\hline $\begin{array}{c}\text { The } \\
\text { serial } \\
\text { number }\end{array}$ & $\begin{array}{c}\text { The flow of water } \\
(\mathrm{L} / \mathrm{h})\end{array}$ & $\begin{array}{c}\text { Residence } \\
\text { time }(\mathrm{h})\end{array}$ \\
\hline 1 & 15 & 4 \\
\hline 2 & 20 & 3 \\
\hline 3 & 30 & 2 \\
\hline 4 & 60 & 1 \\
\hline 5 & 120 & 0.5 \\
\hline
\end{tabular}

The experiment period ended when the hardness value of produced water tended to be flat.

\subsection{Laboratory testing}

The hardness and alkalinity were measured by the Lovibond Spectrodirect multi-parameter water quality tester, and the unit was $\mathrm{mg} / \mathrm{L}\left(\mathrm{CaCO}_{3}\right)$.

$\mathrm{PH}$ was measured by $\mathrm{pH}$ Meter (PHS-3 CPH Meter).

The electrical conductivity was measured by a conductivity meter (Shanghai Lei Magnetic DDSJ- 308 A).

\subsection{The data processing}

The hardness removal amount $\left(\mathrm{g} \mathrm{CaCO}_{3} /\left(\mathrm{m}^{2} . \mathrm{h}\right)\right)$ is calculated by dividing the total hardness change before and after the descaling reaction by the cathode area and time.

The hardness removal rate is calculated by dividing the reduction in hardness by the initial hardness before the reaction. $[7,8]$

\section{Results and discussion}

Five groups of experiments were carried out according to the table, and the results of hardness removal rate were shown in the figure:

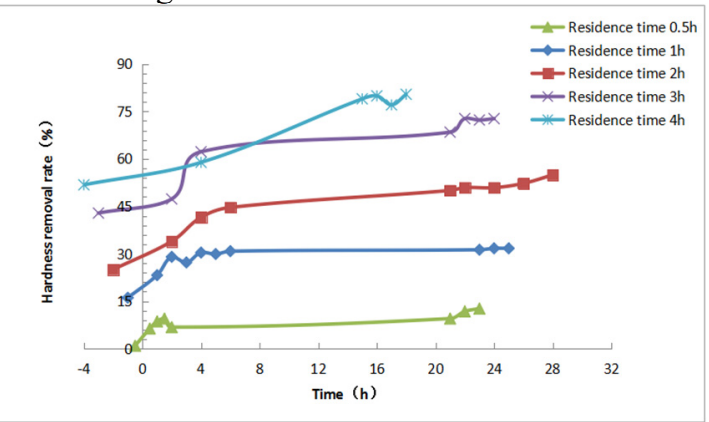

Figure 2. The change of hardness removal rate under different time of water intake

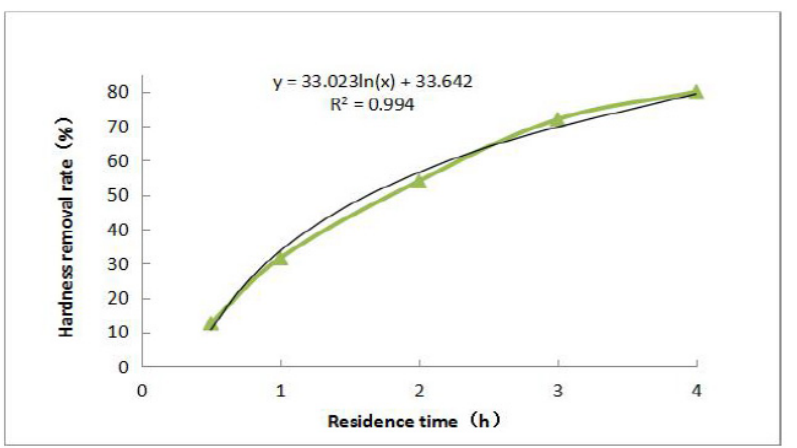

Figure 3. The change of hardness removal rate under different residence time

Fig. 2 shows the change of hardness removal rate of the five groups of experiments under different inlet time (negative number in the abscissa represents static reaction time). As can be seen from Fig. 2, with the progress of the reaction, except for the first experiment, the hardness removal rates of the other four experiments can reach a stable state after $8 \mathrm{~h}$ of reaction.

Taking residence time as the abscissa, the hardness removal rate after the final stability of the five groups of experiments was analyzed, as shown in Fig. 3. the hardness removal rate increases with the extension of residence time, and the hardness removal rate reaches $80 \%$ when the residence time is $4 \mathrm{~h}$. 


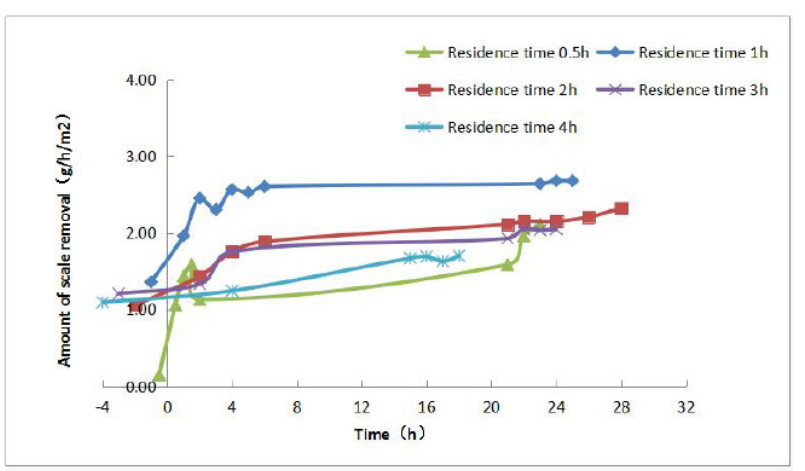

Figure 4. The change of scale removal amount under different time of water intake

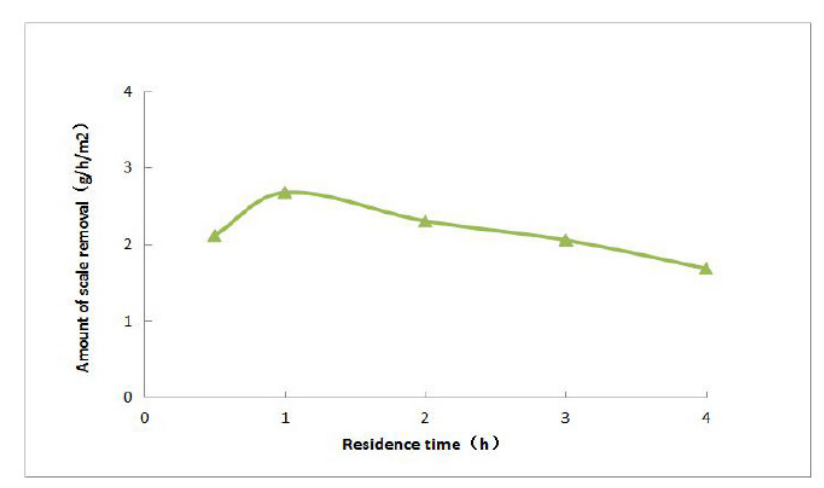

Figure 5. The change of scale removal amount under different residence time

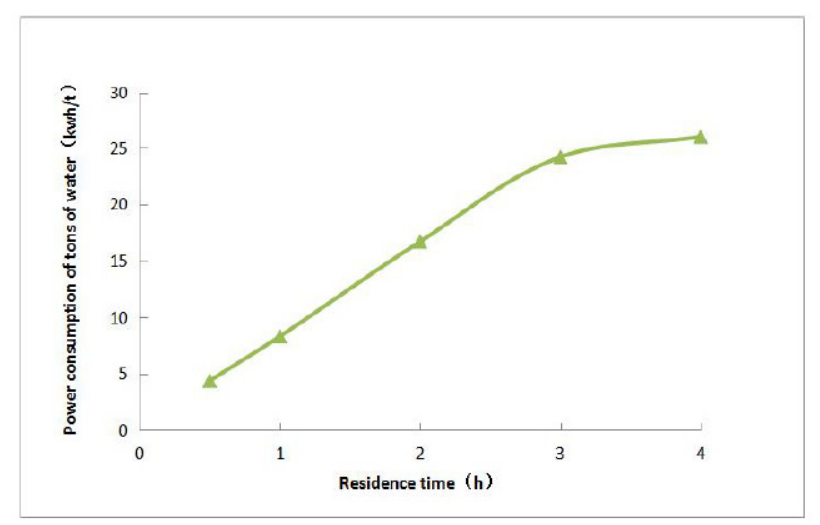

Figure 6. The power consumption of tons of water under different residence time

Fig. 4 shows change of scale removal amount of the five experiments under different inlet time (negative number in the abscissa represents static reaction time). As can be seen from Fig. 4, with the reaction going on, the scale removal amount of the five groups of experiments can reach a stable state after $6 \mathrm{~h}$ of reaction.

Taking residence time as the abscissa, the final stable scale removal amount of the five groups of experiments was analyzed, as shown in Fig. 5. When residence time was $1 \mathrm{~h}$, the scale removal amount reached the maximum value of $2.67 \mathrm{~g} / \mathrm{h} / \mathrm{m}^{2}$ (at this time, the power consumption of tons of water was also at a low value, as shown in Fig.6), and then showed a downward trend. It may be because the residence time is too short, the current velocity is too high, and the disturbance is too intense, which may reduce the combination time of calcium and magnesium with carbonate, so the removal effect of scale is not good. With the extension of residence time, the speed of water flow slows down, and the chance of calcium and magnesium ions in the water contacting with the carbonate near the plate is reduced, and the probability of scaling is also reduced. Therefore, the velocity between plates should be analyzed to find the optimal velocity, which is related to the inflow of water and the layout design of the plate.

Set the hardness of inlet water as $\mathrm{C} 0$, and the hardness of outlet water as $\mathrm{C}$. The value of $\mathrm{C} 0 / \mathrm{C}$ of the five groups of experiments were summarized in Table 3 below, and Fig. 7 was made according to Table 3.

Table 3. The value of $\mathrm{C} 0 / \mathrm{C}$ of the five groups of experiments

\begin{tabular}{|c|c|c|c|c|}
\hline $\begin{array}{c}\text { The } \\
\text { amount of } \\
\text { incoming } \\
\text { water(L/h) }\end{array}$ & $\begin{array}{c}\text { Residence } \\
\text { time(h) }\end{array}$ & $\begin{array}{c}\text { The } \\
\text { hardness } \\
\text { of inlet } \\
\text { water } \\
(\mathrm{mg} / \mathrm{L})\end{array}$ & $\begin{array}{c}\text { The } \\
\text { hardness } \\
\text { of outlet } \\
\text { water } \\
(\mathrm{mg} / \mathrm{L})\end{array}$ & $\mathrm{C} 0 / \mathrm{C}$ \\
\hline 15 & 4 & 224 & 44 & 5.09 \\
\hline 20 & 3 & 224 & 62 & 3.61 \\
\hline 30 & 2 & 224 & 101 & 2.22 \\
\hline 60 & 1 & 236 & 153 & 1.54 \\
\hline 120 & 0.5 & 222 & 195 & 1.14 \\
\hline
\end{tabular}

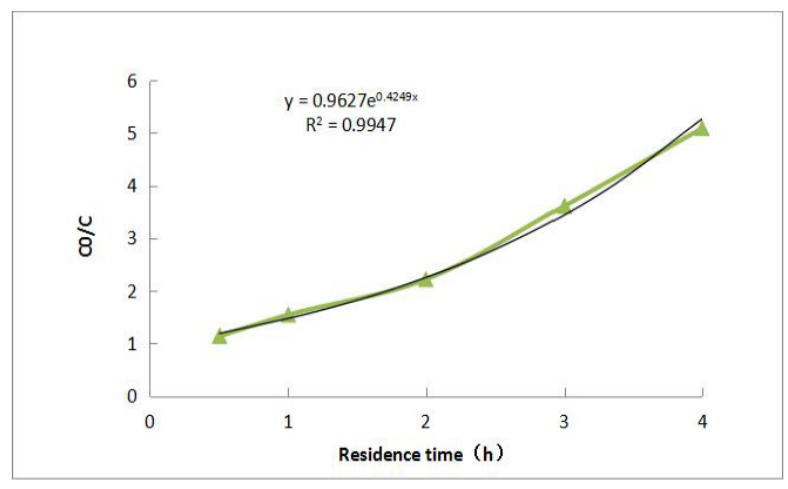

Figure 7. $\mathrm{C} 0 / \mathrm{C}$ under different residence times

It can be considered that the relationship between $\mathrm{C} 0 / \mathrm{C}$ and residence time (the inflow of water) is $\mathrm{y}=0.9627 \mathrm{e}^{(0.4249 \mathrm{x})}$, If it is thought that $\mathrm{C} 0 / \mathrm{C}=\mathrm{Ae}^{(\mathrm{Akt} / \mathrm{V})}$, the cathode area $A=1.59 \mathrm{~m} 2$ and the water quantity $\mathrm{V}=60 \mathrm{~L}$ were substituted, and the reaction constant $K=17.73$ could be obtained. Therefore, it could be considered that the current density of the equipment was $15 \mathrm{~A} / \mathrm{m} 2$, The formula $\mathrm{C} 0 / \mathrm{C}=0.9627 \mathrm{e}^{\left(1.59^{*} 17.73^{*} \mathrm{t} / 60\right)}$ can be used for the removal effect of the water quality under different inflow (residence time).

\section{Conclusions and Suggestions}

The descaling device has obvious treatment effect on the drainage of the converter station. Through experiments, it can be concluded that:

1. When the residence time is from $0.5 \mathrm{~h}$ to $4 \mathrm{~h}$, the hardness removal rate is from $10 \%$ to $80 \%$, and the longer the residence time is, the higher the removal rate is. However, it can not only pursue the high removal rate, because it will lead to the reduction of water treatment. 
2. The maximum amount of scale removal reaches $2.67 \mathrm{~g} / \mathrm{h} / \mathrm{m}^{2}$ at residence time $1 \mathrm{~h}$, so it can be considered that the water velocity between plates has a great influence on the hardness removal effect. Therefore, the position of plates should be reasonably designed and arranged to obtain the optimal flow velocity.

3. When the current density of the device is $15 \mathrm{~A} / \mathrm{m} 2$, the removal effect can be expressed by the formula $\mathrm{C} 0 / \mathrm{C}=0.9627 \mathrm{e}^{(17.73 \mathrm{a} / \mathrm{V})}$ under different water intake (residence time) for the experimental water quality. It is suggested that other water quality tests should be carried out in the future, and the formula should be modified with the experimental results, so that this series of experiments will be of guiding significance to practical engineering.

\section{References}

1. Q. Chen, Study on Flow Characteristics between Vertical Plane Electrodes for Electrochemical Scale Removal, Chemical Engineering and Equipment, 6, 5, (2020).

2. H. Q. Zhang, T. Ling, J. F .Li, Application and Prospect of Electrochemical Technology in Mine Water Treatment, CHINA COAL, 47, 71,(2021).

3. J.P. Wang, Study on Kinetics Characteristics and Process of Electrochemical Scale Removal for Circulating Cooling Water, University of Jinan, 2, (2019).

4. C. C. Wang, J. Shi, B. Y. Xiao, Principle and Application of Water Quality Stabilization Treatment Technology for Electrochemical Circulating Water, Baosteel technology, 64, (2012).

5. X. L. Qu, Study on Descaling of Circulating Water by Electrochemical Method, Dalian Maritime University, 17-20, (2016).

6. H. Xu, M. M. Yuan, Pilot-Scale Experimental Study on Electrochemical Scale Removal Technology, Industrial Water Treatment, 39, 39-41, (2019).

7. Q. R. Pan, Study on Softening and Desalting of Industrial Circulating Water Based on Electrochemical Method, Southeast University, 20-22, (2019).

8. J. H. Sun, Research on Descaling Method of the Industrial Recirculating Cooling Water System, Tianjin University, 18-24, (2013). 